\title{
EVALUATION OF SEDATIVE EFFECTS OF DAILY CONSUMPTION OF YOGHURT IN RATS
}

\author{
HAMDY M. EMBARK ${ }^{1}$ and ABDELMONEIM K. ABDALLA ${ }^{2}$ \\ ${ }^{1}$ Department of Animal Physiology, Faculty of Veterinary Medicine, South Valley University, Qena \\ 83523, Egypt \\ ${ }^{2}$ Department of Food Science, Faculty of Agriculture, South Valley University, Qena \\ 83523, Egypt
}

Received: 30 Sebtember 2019; Accepted: 27 October 2019

\begin{abstract}
Yoghurt is one of the most popular fermented dairy foods worldwide and possesses several health-beneficial properties. Yoghurt provides numerous nutrients and bioactive components which may modulate many physiological and psychological processes. This study aimed to assess the possible sedative effects of daily consumption of yoghurt in normal, healthy rats. The plain yoghurt was made directly using fresh cow's milk and starter culture. Rats were weighed, randomly divided into two groups (12 rats in each group), and orally gavaged once a day for seven consecutive days as follows: Control group (distilled water, $2 \mathrm{ml} / 100 \mathrm{~g} \mathrm{~b}$.wt) and yoghurt group (plain yoghurt, $2 \mathrm{ml} / 100 \mathrm{~g} \mathrm{~b} . \mathrm{wt}$ ). Motor activity and exploratory behavior of the animals were measured actimetry, using the infrared LE8811 Actimeter Panlab system, in order to count the number of global, locomotor, and stereotype activities, number of rearing, total distance travelled, mean velocity/speed, and resting time. Daily consumption of yoghurt was associated with a significant reduction of rat global, locomotor, and stereotyped activities compared to control group. The total distance traveled, mean speed, and number of rearing also decreased but not reaching significance. Interestingly, daily consumption of yoghurt accentuated resting state in rats. Together, these data demonstrate for the first time that daily consumption of yoghurt for seven consecutive days could decrease rat motivity and promote calmness resulting in a sedative effect, which may be effective for the treatment of anxiety and depression.
\end{abstract}

Keywords: Yoghurt; Sedation; Psychomotor Activity; Rats

\section{INTRODUCTION}

Consumption of fermented dairy foods has increased in nearly all world regions, but at different speeds (Deeth and Tamime, 1981). Yoghurt is the major dairy food made from the milk by lactic acid fermentation through the action of Streptococcus thermophilus and Lactobacillus bulgaricus culture (Tamime and Robinson, 2007). In some countries, Lactobacillus helveticus and Lactobacillus lactis, are mixed with the previous starter culture (McKinley, 2005). When a large amount of lactic acid produced, the milk coagulated and called yoghurt (Tamime and Robinson, 1999).

Yoghurt can be classified as plain/natural, fruit or flavored yoghurt based on flavor and set, stirred, drinking or frozen yoghurt based on the manufacturing methods (Shah et al., 2000). Yoghurt

Corresponding author: Hamdy M. Embark E-mail address: h.embark@vet.svu.edu.eg

Present address: Department of Animal Physiology, Faculty of Veterinary Medicine, South Valley University, Qena 83523, Egypt can be also classified into two different groups namely, standard culture yoghurt and bio- or probiotic yoghurt (Chandan and Kilara, 2013).

Yoghurt is considered as a functional highly nutritious food that contains essential nutrients such as carbohydrates, proteins, lipids, vitamins, and minerals (Tamime and Robinson, 2007). Apart from the nutritive constituents, consumers can intake the active bacterial culture and bioactive components formed during fermentation from yoghurt (EFSA, 2010; Zare et al., 2011; Marette et al., 2017). Yoghurt consumption has many health benefits in terms of enhancing immunity, controlling inflammation, modulating gut microbiota, and improving cholesterol metabolism (Frias et al., 2016; Marette et al., 2017).

Yoghurt was regarded as a potential vehicle for probiotic (Tamime and Robinson, 2007; CDC, 2009; Frias et al., 2016; Marette et al., 2017). Probiotic bacteria are living organisms that can inhabit the gut and contribute to the health of the host (Gareau et al., 2010). Accumulating clinical evidence suggests that probiotics can modulate the stress response and 
improve mood and anxiety symptoms in patients with chronic fatigue and irritable bowel syndrome (Silk et al., 2009). Yoghurt also contains several nutrients with potential sleep-promoting properties (Milind and Jyoti, 2014).

In an attempt to understand the impact of daily yoghurt consumption in the modulation of physiological and psychological processes in healthy rats, we undertook an open-field test to evaluate the locomotion and exploration of a novel environment as an index for the fear and anxiety levels. Additionally, to determine some possible sedative effects of daily consumption of yoghurt in rats we evaluated its influence on the three types of information regarding the animal spontaneous motor activity (global, locomotor, and stereotyped activities) and number of rearing.

\section{MATERIALS AND METHODS}

\section{Ethical Approval}

Animal handling and experimentation were performed in line with approved Institutional Animal Care and Use Committee (IACUC\#: 12-214) protocols at the South Valley University (Qena, Egypt) and complied with the ethical standards established by the Egyptian animal welfare laws and policies and followed the national authority (Ministry of Higher Education and Scientific Research, Egypt) guidelines for the detention, use and the ethical treatment of laboratory animals. Also, all animal protocols were approved by the Animal Use Subcommittee and by the Research and Ethical Review Committee of the Faculty of Veterinary Medicine, South Valley University.

\section{Experimental Animals}

Adult male albino rats were purchased from the animal house of the Faculty of Medicine, Assiut University, Assiut, Egypt and shipped to our facility in environmentally controlled ground vehicles. The animals were housed in cages (55 x $40 \times 20-\mathrm{cm})$, under standard laboratory conditions $\left(22 \pm 2{ }^{\circ} \mathrm{C}\right.$ temperature, $60 \pm 5 \%$ humidity, in a 12 -h light-dark cycle), with food and water ad libitum. Environmental factors (such as cage type and size, colony size, bedding, and environmental enrichment) were standardized between cages. They were kept for two weeks under this condition to adapt the laboratory conditions before the start of the experiment.

\section{Yoghurt's Starter Culture}

Commercial yoghurt culture (YC-X11, Thermophilic yoghurt culture - YoFlex ${ }^{\circledR}$ ), containing Streptococcus Thermophilus and Lactobacillus Bulgaricus, was obtained from CHR-Hansen, Horsholm, Denmark.

\section{Plain Cow's milk Yoghurt preparation}

Fresh cow's milk was pasteurized at $90^{\circ} \mathrm{C}$ for $20 \mathrm{~min}$ and cooled to $45^{\circ} \mathrm{C}$. After cooling, pasteurized cow's milk was inoculated with $3 \%(\mathrm{v} / \mathrm{v})$ Yoghurt's starter culture (YC-X11) and incubated at $45^{\circ} \mathrm{C}$ for $4 \mathrm{~h}$ until complete coagulation (Aswal et al., 2012). Yoghurt samples were cooled to refrigerator temperature $\left(\sim 4 \pm 1^{\circ} \mathrm{C}\right)$ and stored for 7 days.

\section{Experimental Design}

The experiment was carried out on twenty-four adult male albino rats (200-250 g) distributed in two groups of 12 animals each treated as follows:

Group I (Control): Rats were gavaged orally with distilled water $(2 \mathrm{ml} / 100 \mathrm{~g}$ body weight/day) for one week and fed unrestricted amounts of a standard chow diet.

Group II (Yoghurt): Rats were gavaged orally with plain yoghurt (2 ml/100 g body weight/day) for one week and fed unrestricted amounts of a standard chow diet. The dose of yoghurt was $2 \mathrm{ml} / 100 \mathrm{~g}$ body weight/day, whose consumption is equivalent to the children consumption of $100 \mathrm{ml}$ yoghurt/day (WHO, 2006).

\section{Behavioral studies}

The open field activity measurement was performed as previously described (Prut and Belzung, 2003; Araki et al., 2015). Briefly, rat's motor activity and exploration of a novel environment were assessed using an infrared LE8811 Actimeter system (Panlab, Barcelona, Spain). The test apparatus consisted of a $45 \mathrm{~cm}$ (width) x $45 \mathrm{~cm}$ (depth) arena of black plexiglass enclosed with four clear acrylic walls (35 $\mathrm{cm}$ in height) (Fig. 1). A square frame mounted outside of the arena created a 16 x 16 grid of intersecting infrared beams used to track the motor activity of each rat in real-time. A second frame placed above the lower frame was used to track the number rearing of each rat, set to detect hind-leg rearing.

Locomotor measures were recorded using ActiTrack software (Panlab), which uses infrared beam data to calculate the following parameters: (i) number of spontaneous global activity (total number of beam breaks); locomotion with displacement, and stereotyped movements without displacement; (ii) number of rearing; (iii) total distance travelled in the actimeter $(\mathrm{cm})$; (iv) mean velocity/speed $(\mathrm{cm} / \mathrm{s})$; and (v) time spent in resting (in sec or as \%). The recorded data are easily exported in a format compatible with the Excel program for Windows, through SeDaCom32 computer software.

In the $7^{\text {th }}$ day, testing was conducted during the light phase between $07: 30 \mathrm{~h}$ and 12:30 $\mathrm{h}$ for all rats. Rats were brought into the testing room in their home cage a half hour prior to testing for habituation. Each rat was then released near the wall of the arena and left undisturbed to explore freely the new environment for a period of $10 \mathrm{~min}$. This minimized stress to the animals. Measurements were only recorded during the final $5 \mathrm{~min}$ (first $5 \mathrm{~min}$ was used only for animal acclimatization). 
During testing, the lighting of the experimental room was about $400 \mathrm{~lx}$ so as not to inhibit normal exploratory behavior. At the end of testing, the rat was removed and returned to its home cage and the surface and walls of the arena were wiped clean with $30 \%$ isopropanol.

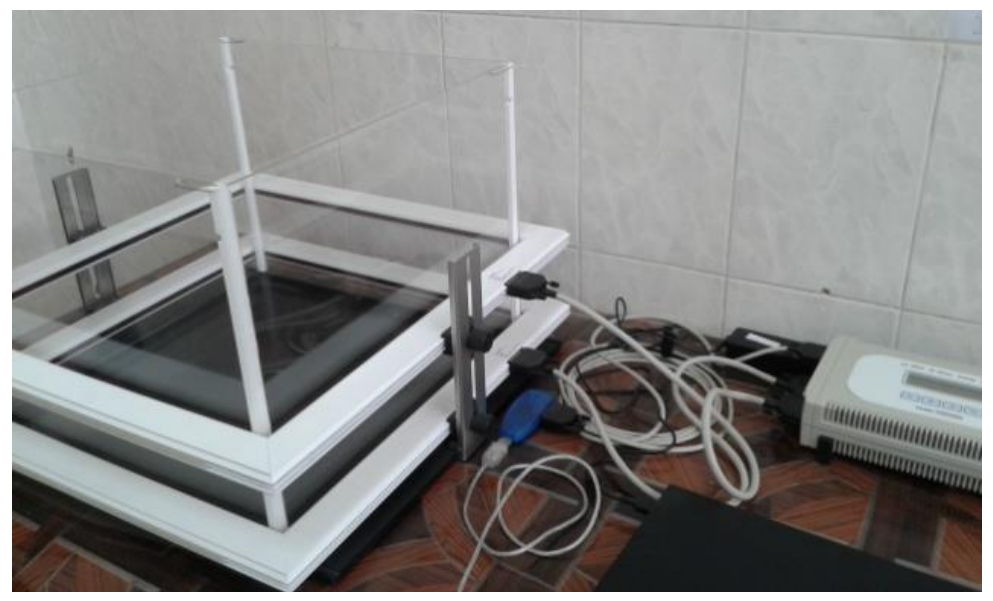

Fig. 1: Infrared LE8811 Actimeter (Panlab) system for motor activity tracking in rodents. A Novel open-field apparatus connects with a sample ActiTrack real-time tracking output. Lower frame is used to track motor activity, while the upper frame tracks number of rearing.

\section{Data Analysis and Statistics}

All data were expressed as the mean \pm standard error of the mean (SEM). Plots were constructed with SigmaPlot 2001 for Windows, Version 7.0 software (SPSS Inc., Chicago, IL, USA). Statistical analysis of the behavioral data was done with Microcal ${ }^{\mathrm{TM}}$ Origin 6.0 software (Microcal Software Inc., Northampton, MA, USA) by student's $t$ test. Statistical significance was established when $P<0.05$.

\section{RESULTS}

To study the effects of daily consumption of yoghurt on modulation of the physiological and emotional states in normal, healthy rats, the plain cow's milk yoghurt has been administered orally via gavage for seven consecutive days. Sedative effect corresponded to a decrease in the percentage of motor activity compared with the control group (Girzu et al., 1997).

\section{Effect of daily yoghurt consumption on the spontaneous global activity}

Spontaneous global activity consisted of the sum of locomotion and stereotyped movements. The oral gavage of yoghurt $(2 \mathrm{ml} / 100 \mathrm{~g} \mathrm{~b} \mathrm{wt} /$ day $)$ for 7 days was associated with a significant $(p<0.05)$ decrease of rat spontaneous global activity (243.64 \pm 41.38), compared to control group (421.25 \pm 68.66$)$ in this experimental behavioral model using normal, healthy rats (Fig. 2).

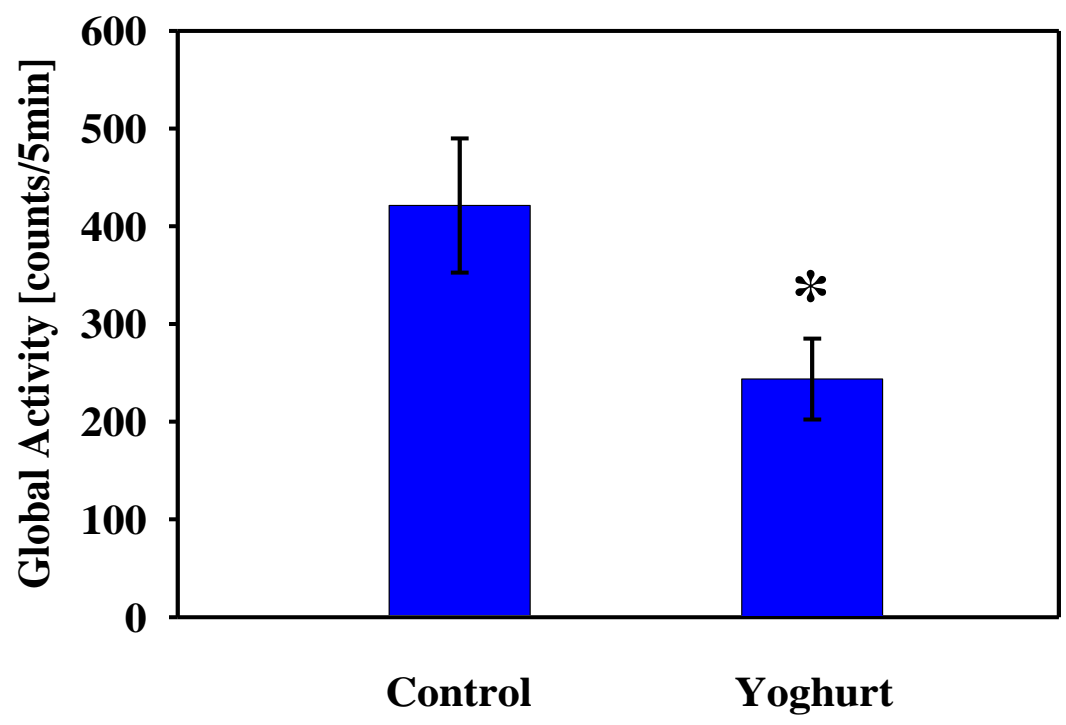

Fig. 2: Global activity in the open-field test. Data shown represent the mean ( \pm SEM) infrared beam breaks by adult male albino rats 7 days after oral administration of distilled water (in control group, $n=11$ rats) or plain yoghurt (in yoghurt group, $\mathrm{n}=12$ rats). $* p<0.05$ vs control. 
Effect of daily yoghurt consumption on the locomotor activity (locomotion)

Ambulatory locomotor activity (locomotion) refers to the movement made by the rat during the analyzed interval, i.e., distance walked in each sample where the position of the rats is different from the position of the previous sample and different from the position of the second sample back in time (Carino et al.,
2017).

Daily oral administration of yoghurt significantly $(p<0.05)$ decreased the locomotor activity of rats $(226.00 \pm 37.78)$, compared to control group $(388.92 \pm 63.81)$ in this experimental behavioral model (Fig. 3).

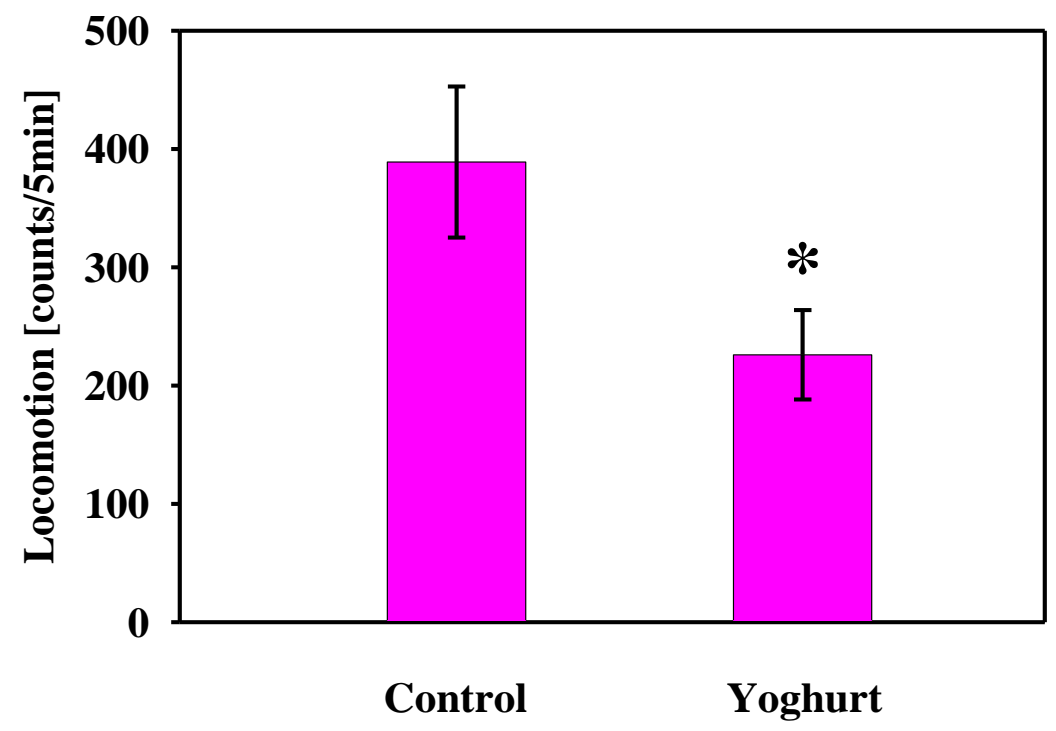

Fig. 3: Locomotion in the open-field test. Data shown represent the mean ( \pm SEM) infrared beam breaks by adult male albino rats 7 days after oral administration of distilled water (in control group, $\mathrm{n}=11$ rats) or plain yoghurt (in yoghurt group, $\mathrm{n}=12$ rats). $* p<0.05$ vs control.

Effect of daily yoghurt consumption on the stereotyped movements

Stereotyped movements during the analyzed interval, indicate the number of samples where the position of the rats is different from the position of the previous sample and equal to the position of the second sample back in time (Carino et al., 2019).

The treatment with yoghurt in rats (yoghurt group) was associated with a statistically significant $(p<0.05)$ decrease of the rat stereotyped movements (17.64 \pm 4.07), comparing with the control group (32.33 \pm 5.25), during the session of experimentation (Fig. 4).

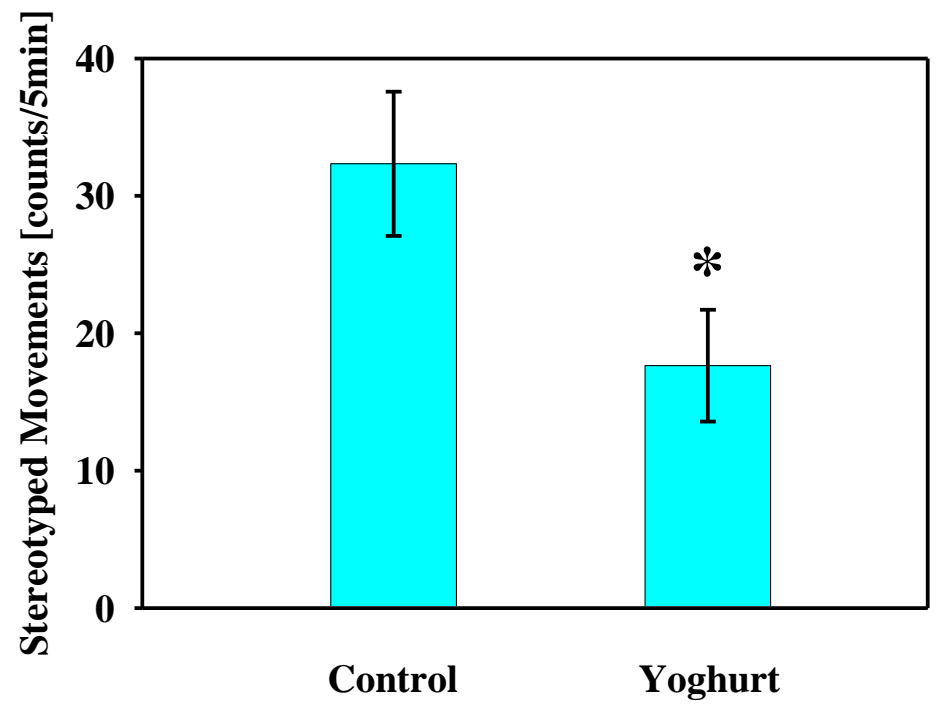

Fig. 4: Stereotyped movements in the open-field test. Data shown represent the mean $( \pm S E M)$ infrared beam breaks by adult male albino rats 7 days after oral administration of distilled water (in control group, $\mathrm{n}=11$ rats) or plain yoghurt (in yoghurt group, $\mathrm{n}=12$ rats). $* p<0.05$ vs control. 
Effect of daily yoghurt consumption on the number of rearing

The animals administered with yoghurt showed a marked decrease of the number of rearing (3.27士 $0.76)$, but not reaching significance compared to control group $(8.58 \pm 3.12)$, in this behavioral test (Fig. 5A). While, there was nearly no effect of yoghurt consumption on mean duration of rearing compared to control group (Fig. 5B).
A

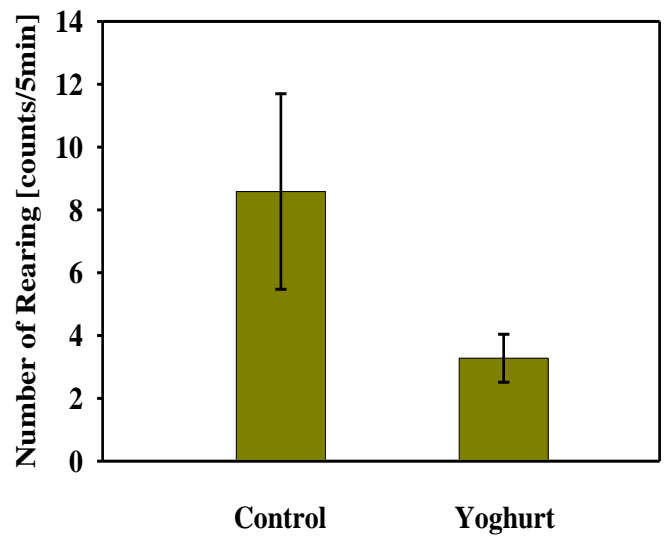

B

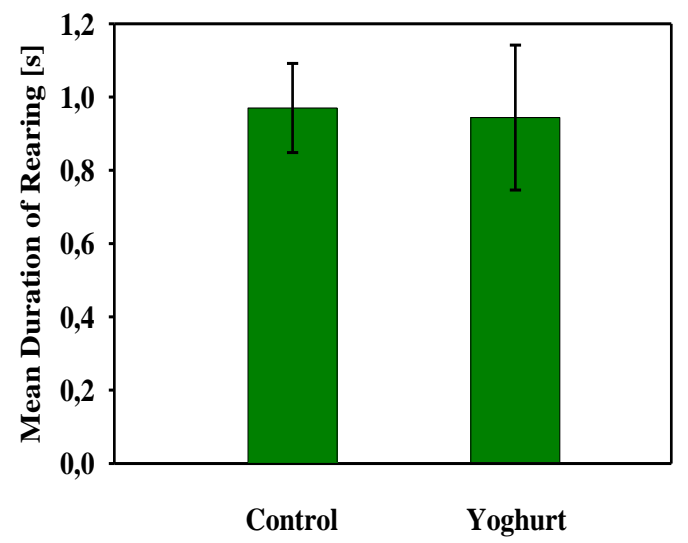

Fig. 5: Number and mean duration of Rearing in the open-field test. Data shown represent the mean $( \pm$ SEM) number of rearing (A) and rearing duration in seconds (B) of adult male albino rats 7 days after oral administration of distilled water (in control group, $\mathrm{n}=11$ rats) or plain yoghurt (in yoghurt group, $\mathrm{n}=12$ rats).

Effect of daily yoghurt consumption on the total distance travelled

The animals administered yoghurt showed a marked decrease of the total distance travelled $(324.35 \pm$
65.31), but not reaching significance compared to control group $(610.88 \pm 121.91)$, in this behavioral test (Fig. 6).

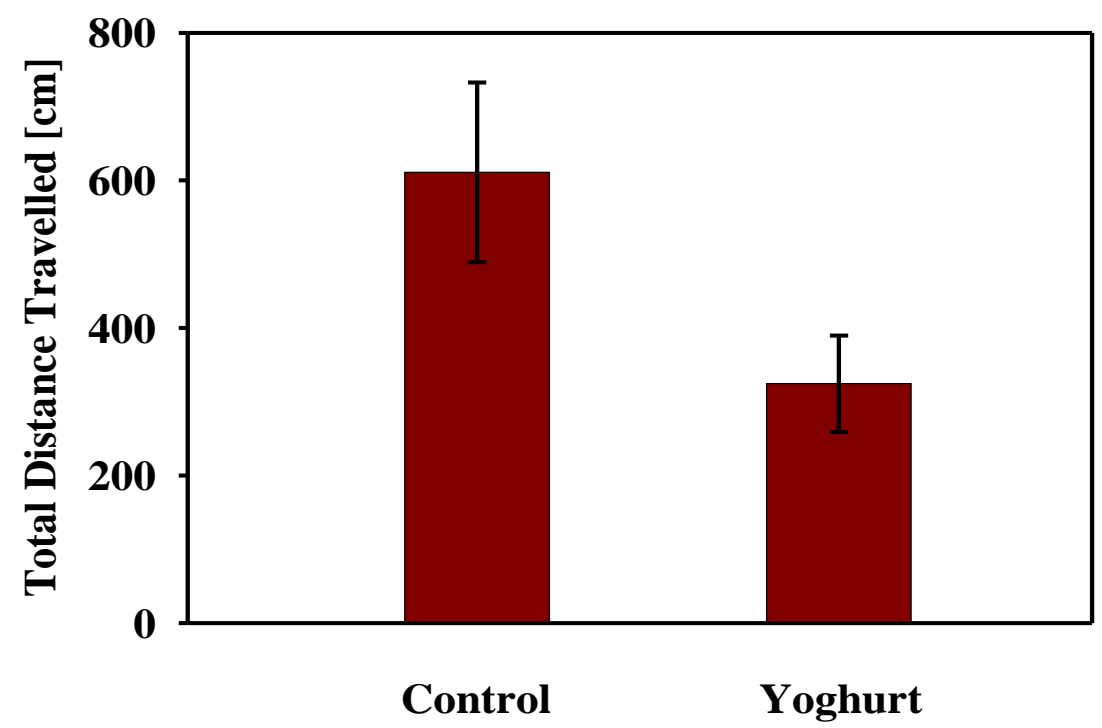

Fig. 6: Total distance travelled $(\mathrm{cm})$ in the open-field test. Data shown represent the mean $( \pm$ SEM) total distance travelled $(\mathrm{cm})$ by adult male albino rats 7 days after oral administration of distilled water (in control group, $\mathrm{n}=11$ rats) or plain yoghurt (in yoghurt group, $\mathrm{n}=12$ rats).

Effect of daily yoghurt consumption on the mean velocity/speed

The animals which were administered with yoghurt showed a great decrease of mean velocity/speed
(1.08 \pm 0.22$)$, but not reaching significance, compared to control group $(2.03 \pm 0.41)$, in this behavioral test (Fig. 7). 


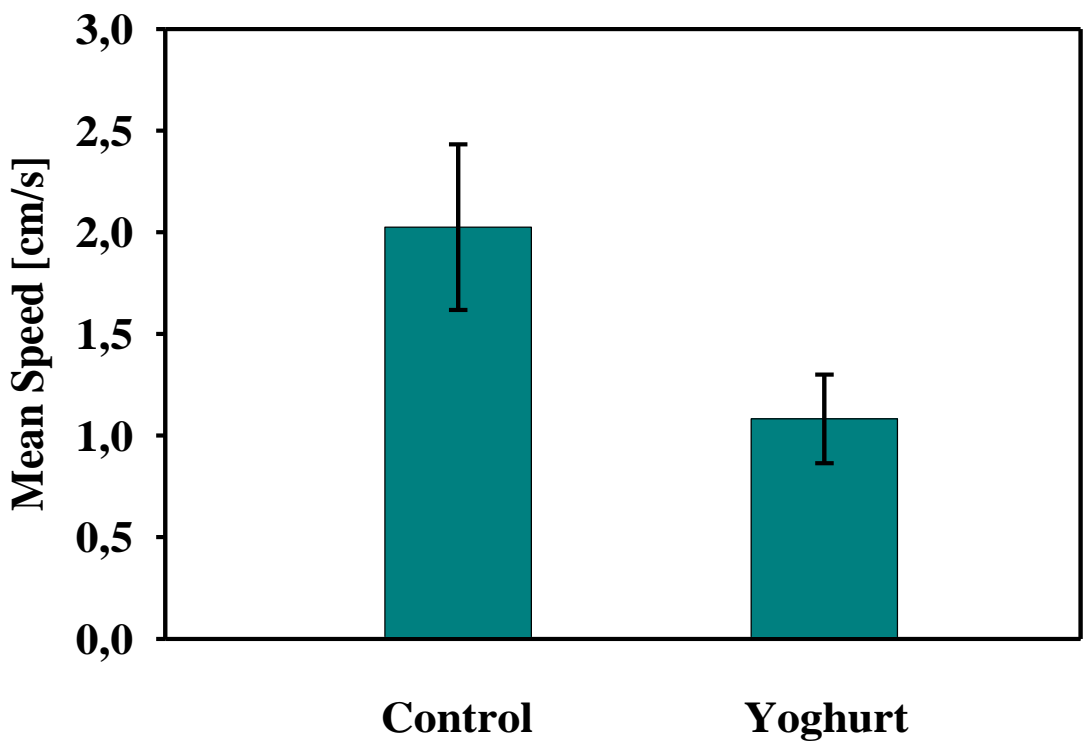

Fig. 7: Average speed in the open-field test. Data shown represent the mean $( \pm \mathrm{SEM})$ average speed $(\mathrm{cm} / \mathrm{s})$ of adult male albino rats 7 days after oral administration of distilled water (in control group, $\mathrm{n}=11$ rats) or plain yoghurt (in yoghurt group, $\mathrm{n}=12$ rats).

Effect of daily yoghurt consumption on the resting time

Resting time consists of sleeping, cleaning and eating time. The animals which were administered with yoghurt (yoghurt group) showed a significant $(\mathrm{p}<0.05)$ increase of mean resting time $(232.11 \pm$ 10.47), compared to control group (183.62 \pm 16.59$)$, in this behavioral test (Fig. 8A). The percentage of resting time of yoghurt fed animals was increased by $16 \%$ compared to control group (Fig. 8B).
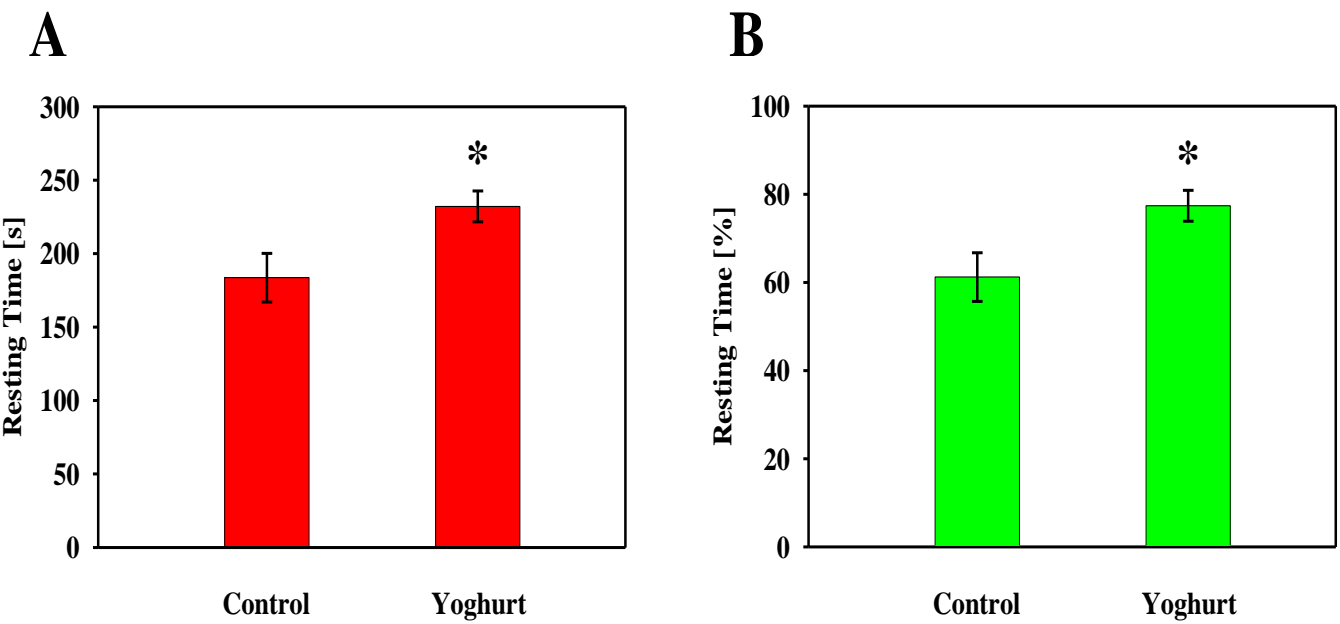

Fig. 8: Resting time in the open-field test. Data shown represent the mean ( \pm SEM) rest time in seconds (A) or as the percentage of total time, 5 minutes $(\mathbf{B})$, of adult male albino rats 7 days after oral administration of distilled water (in control group, $\mathrm{n}=11$ rats) or plain yoghurt (in yoghurt group, $\mathrm{n}=12$ rats). ${ }^{*} \mathrm{p}<0.05$ vs control.

\section{DISCUSSION}

The open-field test (actimetry) is a widely used model for the evaluation of emotional responses of the animals, especially the rodents ((Boissier and Simon, 1965). We use a fully-automated infrared actimeter system to record the spontaneous psychomotor abilities and cognitive functions in normal, healthy rats. We obtained the number of locomotor activity, stereotyped movements, and rearing, in a definite session of time. The locomotor activity and number of rearing indirectly signify the animal state of fear and anxiety of the new environment (Kas et al., 2008; Hart et al., 2010). On the other hand, the stereotype 
movements suggest the self-maintenance of animal personal hygiene (Lynch et al., 2011).

Locomotion is dependent on proper control of muscle activity. Muscle relaxation is commonly associated with sedation (Bonetti et al., 1982), which may be indicated by less locomotion in the actimeter. Myorelaxation may also impair the exploratory activity of the rats and thus affect their performance in the actimeter. The obtained results show that in the experimental behavioral model using normal, healthy rats, yoghurt consumption for seven consecutive days diminished both motor activity and the number of rearing. This could correspond somehow to sedation in humans.

The previous study by Jaatinen et al. (2014) showed that daily consumption of yoghurt enriched with bioactive components may aid in stress coping. Yoghurt rich in lactobacillus, a probiotic bacterium, may help alleviate symptoms of depression and anxiety, a finding that could lead to new strategies for treating psychiatric conditions (Marin et al., 2017) and insomnia (Yamamura et al., 2009). Moreover, tryptophan is present in small amounts in most protein foods and in higher amounts in yoghurt, milk, oats, bananas, dates, poultry, eggs and peanuts (Kitano et al., 2014). After consumption, tryptophan is metabolically transformed to bioactive metabolites, including serotonin and melatonin (Friedman, 2018). Both of these are brain chemicals that induce relaxation and sleepiness (Peuhkuri et al., 2012).

In this study, daily yoghurt consumption produces a significant decrease in motivity compared with rats treated with distilled water alone. Furthermore, daily consumption of yoghurt accentuates resting time in normal, healthy rats. This sedative and hypnotic effect of the yoghurt could contribute to impacts of yogurt's components (e.g., probiotics, tryptophan, and vitamins) that induce relaxation and calmness.

\section{CONCLUSIONS}

The present study demonstrates for the first time that daily consumption of plain cow's milk yoghurt possesses significant sedative and hypnotic-like features that may have a potential therapeutic value for treatment of anxiety and depression symptoms in patients with sustained and systemic convulsions. However, further precise studies are required to verify its activity in other experimental models and its precise mechanism of action should be determined.

\section{CONFLICTS OF INTEREST}

The authors declare that there are no conflicts of interest regarding publication of this paper.

\section{ACKNOWLEDGEMENTS}

This work was supported by grant No. 2505 from the Science and Technology Development Fund (STDF), Egypt. The authors wish to thank all members and professors of the Department of Animal Physiology, Faculty of Veterinary Medicine, South Valley University, Qena, Egypt, and of Food Science Department, Faculty of Agriculture, South Valley University, Qena, Egypt, for their constant encouragement and kind help.

\section{REFERENCES}

Araki, R.; Hiraki, Y.; Nishida, S.; Kuramoto, N.; Matsumoto, K. and Yabe, T. (2015): Epigenetic regulation of dorsal raphe GABA associated with isolation-induced abnormal responses to social stimulation in mice. Neuropharmacology. 101: 1-12.

Aswal, P.; Shukla, A. and Priyadarshi, S. (2012): Yoghurt: Preparation, Characteristics and Recent Advancements. Cibtech Journal of BioProtocols, 1, 32-44.

Boissier, J.R. and Simon, P. (1965): Action of caffeine on the spontaneous motility of the mouse. Arch. Int. Pharmacocyn. 158, 212-221.

Bonetti, E.P.; Pieri, L.; Cumin, R.; Schaffner, R.; Pieri, M.; Gamzu, E.R.; Müller, R.K. and Haefely, W. (1982): Benzodiazepine antagonist Ro 15-1788: neurological and behavioral effects. Psychopharmacology (Berl). 78, 8-18.

Carino, A.; Cipriani, S.; Marchianò, S.; Biagioli, M.; Santorelli, C.; Donini, A.; Zampella, A.; Monti, M.C. and Fiorucci, S. (2017): BAR502, a dual FXR and GPBAR1 agonist, promotes browning of white adipose tissue and reverses liver steatosis and fibrosis. Sci. Rep. 7, 42801.

Carino, A.; Marchianò, S.; Biagioli, M.; Bucci, M.; Vellecco, V.; Brancaleone, V.; Fiorucci, C.; Zampella, A.; Monti, M.C.; Distrutti, E. and Fiorucci, S. (2019): Agonism for the bile acid receptor GPBAR1 reverses liver and vascular damage in a mouse model of steatohepatitis. FASEB J. 33, 2809-2822.

CDC (2009): Supply Management. http://www. cdc.ca/cdc/index_en.asp?caId=812 (accessed April 25, 2009).

Chandan, R.C. and Kilara, A. (2013): Manufacturing yogurt and fermented milks; 2nd Edn.; John Wiley and Sons: Chichester, UK pp 297-317

Deeth, H. and Tamime, A. (1981): Yoghurt: nutritive and therapeutic aspects, J. Food Prot. 44, 7886.

EFSA (2010): Scientific Opinion on the substantiation of health claims related to yoghurt cultures and improving lactose digestion. EFSA Journal 8, 1763-1781. 
Frias, J.; Martinez-Villaluenga, C. and Peñas, E. (2016): Fermented foods in health and disease prevention; Elsevier: London, UK

Friedman, M. (2018): Analysis, Nutrition, and Health Benefits of Tryptophan. Int. J. Tryptophan Res. 11, 1-12.

Gareau, M.G.; Sherman, P.M. and Walker, W.A. (2010): Probiotics and the gut microbiota in intestinal health and disease. Nat. Rev. Gastroenterol. Hepatol. 7, 503-514.

Girzu, M.; Carnat, A.; Privat, A.M.; Fialip, J.; Carnat, A.P. and Lamaison, J.L. (1997): Sedative activity in mice of a hydroalcohol extract of Hypericum perforatum L. Phytotherapy Research 11, 395-397

Hart, P.C.; Bergner, C.L.; Smolinsky, A.N.; Dufour, B.D.; Egan, R.J.; Laporte, J.L. and Kalueff, A.V. (2010): Experimental models of anxiety for drug discovery and brain research. Methods Mol. Biol. 602: 299-321.

Jaatinen, N.; Korpela, R.; Poussa, T.; Turpeinen, A.; Mustonen, S.; Merilahti, J. and Peuhkuri, K. (2014): Effects of daily intake of yoghurt enriched with bioactive components on chronic stress responses: a double-blinded randomized controlled trial. Int. J. Food Sci. Nutr. 65, 507-514.

Kas, M.J.; De Mooij-van Malsen, A.J.; Olivier, B.; Spruijt, B.M. and Van Ree, J.M. (2008): Differential genetic regulation of motor activity and anxiety-related behaviors in mice using an automated home cage task. Behav. Neurosci., 122: 769-776.

Kitano, N.; Tsunoda, K.; Tsuji, T.; Osuka, Y.; Jindo, T.; Tanaka, K. and Okura, T. (2014): Association between difficulty initiating sleep in older adults and the combination of leisuretime physical activity and consumption of milk and milk products: a cross-sectional study. BMC Geriatr. 14, 118-125.

Lynch, J.J.; 3rd, Castagné, V.; Moser, P.C. and Mittelstadt, S.W. (2011): Comparison of methods for the assessment of locomotor activity in rodent safety pharmacology studies. J. Pharmacol. Toxicol. Methods, 64: 74-80.

Marette, A.; Picard-Deland, E. and Fernandez, M.A. (2017): Yogurt: Roles in nutrition and impacts on health; CRC Press: Boca Raton USA 192 pp.

Marin, I.A.; Goertz, J.E.; Ren, T.; Rich, S.S.; Onengut-Gumuscu, S.; Farber, E.; Wu, M.; Overall, C.C.; Kipnis, J. and Gaultier, A. (2017): Microbiota alteration is associated with the development of stress-induced despair behavior. Sci. Rep. 7, 1-10.
Mckinley, M.C. (2005): The nutrition and health benefits of yoghurt. International Journal of Dairy Technology 58, 1-12.

Milind, P. and Jyoti, M. (2014): Curd: A sedative with a bonus bowl of useful side effects. Int. Res. J. Pharm. 5: 131-135.

Peuhkuri, K.; Sihvola, N. and Korpela, R. (2012): Diet promotes sleep duration and quality. Nutr. Res. 32, 309-319.

Prut, L. and Belzung, C. (2003): The open field as a paradigm to measure the effects of drugs on anxiety-like behaviors: a review. Eur. J. Pharmacol. 463: 3-33.

Shah, N.P.; Ali, J.F. and Ravula, R.R. (2000): Populations of Lactobacillus acidophilus, Bifidobacterium spp. and Lactobacillus casei in commercial fermented milk. Biosci. Microflora 19, 35-39.

Silk, D.B.; Davis, A.; Vulevic, J.; Tzortzis, G. and Gibson, G.R. (2009): Clinical trial: The effects of a trans-galactooligosaccharide prebiotic on faecal microbiota and symptoms in irritable bowel syndrome. Aliment Pharmacol. Ther. 29, 508-518.

Tamime, A.Y. and Robinson, R.K. (1999): Packaging. In: Yoghurt Science and Technology; Tamine A.K., Robinson R.K., Eds.; 2nd Edn.; Woodhead Publishing: Cambridge, UK pp 90103.

Tamime, A.Y. and Robisons, R.K. (2007): Background to Manufacturing Practice. In Tamime and Robinson's Yogurt: Science and Technology; 3rd Edn.; Woodhead Publishing: Cambridge, UK pp 11-118.

WHO (2006): Food and nutrition policy for schools: A tool for the development of school nutrition programmes in the European Region. Programme for Nutrition and Food Security. WHO Regional Office for Europe. Copenhagen.

Yamamura, S.; Morishima, H.; Kumano-go, T.; Suganuma, N.; Matsumoto, H.; Adachi, H.; Sigedo, Y.; Mikami, A.; Kai, T.; Masuyama, A.; Takano, T.; Sugita, Y. and Takeda, M. (2009): The effect of Lactobacillus helveticus fermented milk on sleep and health perception in elderly subjects. Eur. J. Clin. Nutr. 63, 100105.

Zare, F.; Boye, J.I.; Orsat, V.; Champagne, C.P. and Simpson, B.K. (2011): Microbial, physical and sensory properties of yogurt supplemented with lentil flour. Food Research International $44,2482-2488$. 


\section{تقييم التأثيرات المهلئة للاستهلاك اليومي للزبادي في الفئران \\ حمدي أمبارك ، عبل المنعم عبل الله}

E-mail: h.embark@vet.svu.edu.eg Assiut University web-site: www.aun.edu.eg

الزبادي هو واحد من منتجات الألبان المخمرة الأكثر شعبية في جميع أنحاء العالم وله العديد من الفوائد الصحية. يوفر العديد من

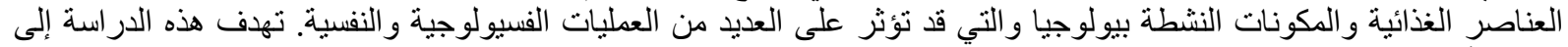

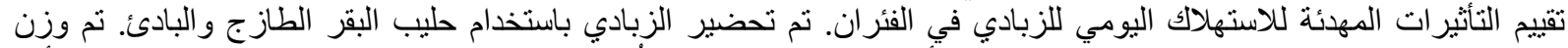

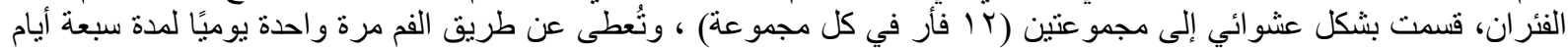

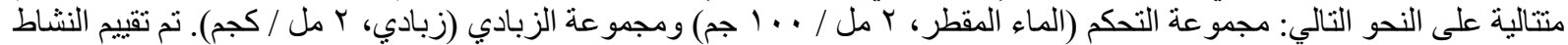

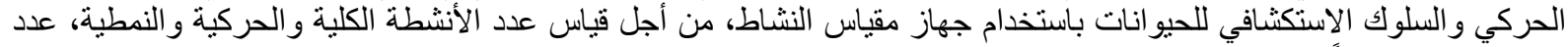

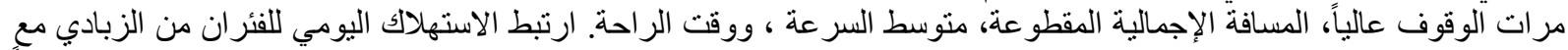

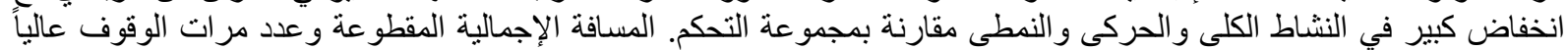

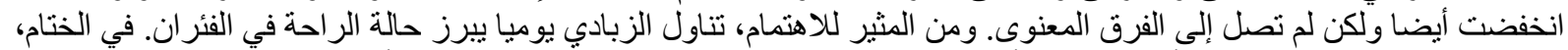

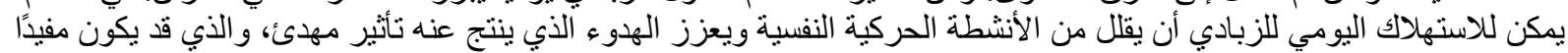
في الطب في علاج بعض المشئل للزب النفسية مثل القلق و الإكتئاب. 